\title{
Patient satisfaction - indicator anesthesia assessment
}

\begin{abstract}
Patient satisfaction is an important indicator of anesthesia evaluation. In near future anesthesiologists will be evaluate not only on the level of theoretical knowledge, manual skills and management of homeostasis during anesthesia and intensive care, but also attentive to the patient, the possibility of achieving psycho-emotional contact, and a positive emotional state of the patient.
\end{abstract}

Keywords: Patient satisfaction, Anesthesia quality, Anesthesia assessmen
Volume 9 Issue I - 2017

\author{
Koriachkin VA, Zabolotskiy DV, Ivanov DO, \\ Alexandrovich YS, Zhikharev VA \\ Vreden Russian Research Institute of Traumatology and \\ Orthopedics, Saint Petersburg State Pediatric Medical University \\ of Health Ministry of Russia, Russia
}

Correspondence: Victor A Koriachkin,Vreden Russian Research Institute of Traumatology and Orthopedics, SaintPeterburg, Russia, Email vakoryachkin@rniito.ru

Received: October 31, 2017 | Published: November 06, 2017

\section{Introduction}

Traditionally, the evaluation of the results of anesthetic support includes changes in hemostatic parameters during surgery, the intensity of postoperative pain, postoperative nausea and vomiting, shakes, cognitive impairment, etc. ${ }^{1}$ In addition, such criteria as the number of complications, the possibility of early rehabilitation, the impact on outcomes, including the likelihood of a lethal outcome. ${ }^{2}$ Nevertheless, some authors believe that these indicators do not fully reflect the quality of anesthesia and are surrogate. ${ }^{3}$

At the end of the last century, the most important provisions for patients were identified, such as the availability of medical care, understandable and in an accessible way informing the patient and his loved ones, respect for the patient's values, his preferences and needs, reducing fear and anxiety in the perioperative period, physical comfort, qualitative analgesia, constant care with the attraction of a relative and close friends. ${ }^{4}$

The aim of this review is to examine the patient's satisfaction as a criterion of the quality of anesthesia.

\section{Material and methods}

The publications included in the databases MEDLINE, PUBMED, COCHRANE, materials of such organizations as the American Society of Anesthesiologists, American Society of Regional Anesthesia, European Society of Anaesthesiology, Agency for Healthcare Research and Quality, National Guideline satisfaction of patient Clearinghouse.

\section{Results and discussion}

In recent years, a fundamentally new aspect has begun to be discussed - the patient's view of the medical care provided, taking into considering his views on both the upcoming therapy methods and their results. ${ }^{5}$ In regarding these circumstances, arose the term "patient satisfaction". The patient satisfaction after anesthesia - the result, the ratio of expectations and what the patient actually experienced is a very difficult task, because it depends on cultural, socio-demographic, emotional, etc. factors.

At present, the assessment of satisfaction is mainly carried based on of the sociological approach, which consists in examining the patients' opinion about medical care by interview. Most questionnaires include such issues as the quality of information provided to the patient, assessment of contact with staff, psycho-emotional state (anxiety, anxiety, fear, etc.), quality of care for the patient etc. Detailed information on methods for assessing satisfaction can be found in the article Barnett et al. ${ }^{6}$ High-quality studies of patient satisfaction with anesthesia are rare. ${ }^{7}$

Very important is the empathic attitude of an anesthesiologist to a patient who wants to feel safe and needs psychological support. ${ }^{8}$ Provision in the preoperative period to the patient of exhaustive information about anesthesia, discussion with the patient of the choice of the method are the most important factors affecting the satisfaction with anesthesia. Moreover, it is shown that patients need more information in case of the proposed regional anesthesia, in comparison with general anesthesia.9 It is shown that most patients prefer a joint non-paternalistic decision making concerning the choice of the method of anesthesia. Moreover, a conversation with several specialists increases the satisfaction of the patient, whereas one conversation with an anesthesiologist only, on the contrary, satisfaction reduces. ${ }^{10}$

Very important is the post-operative communication of the anesthesiologist with the patient with the purpose of emotional support and, if necessary, correction of the therapy, which also contributes to the patient's satisfaction. Unfortunately, only about $60 \%$ of patients can correctly identify the doctor who conducted anesthesia. ${ }^{11}$ The general level of patient satisfaction with anesthesia is high: from 10811 patients, $96.8 \%$ were fully satisfied, $2.3 \%$ were partially satisfied, only $0.9 \%$ were not satisfied. ${ }^{12}$ Attention is drawn to the fact that the choice of anesthesia method - regional or general anesthesia, had no significant effect on patient satisfaction. Interestingly, a correlation was found between patient satisfaction in hospital care and the risk of re-hospitalization: the higher the overall satisfaction level at discharge, the lower the rate of re-hospitalization. ${ }^{13}$ Thus, patient satisfaction is a feedback tool and this concept can be used to assess the quality of hospital management.

\section{Conclusion}

Patient satisfaction is an important integral indicator of the evaluation of anesthesia. There is every reason to believe that in the future the work of anesthesiologists will be evaluated not only in terms of their theoretical training, practical skills and management of homeostasis indicators during anesthesia and intensive care, but also in a sensitive and considerate attitude to the patient, the possibility of reaching a psychoemotional contact creating some positive dynamics of the emotional state of the patient. 


\section{Acknowledgments}

None.

\section{Funding details}

None.

\section{Conflicts of interest}

Authors declare that there is no conflict of interest.

\section{References}

1. Srilatha B, Hima Bindu A. A Retrospective Review on Complications related to Anesthesia. J Anesthe Clinic Res. 2012;3:180.

2. Moro ET, Silva MA, Couri MG, et al. Quality of recovery from anesthesia in patients undergoing orthopedic surgery of the lower limbs. Rev Bras Anestesiol. 2016;66(6):642-650.

3. Lauritsen J, Møller AM. Publications in anesthesia journals:quality and clinical relevance. Anesth Analg. 2004;99(5):1486-1491.

4. Heidegger T, Saal D, Neubling M. Patient satisfaction with anaesthesia - Part 1: Satisfaction as part of outcome - and what satisfies patients. Anaesthesia. 2013;68(11):1165-1172.

5. Stiggelbout AM, Van der Weijden T, De Wit MP, et al. Shared decision making: really putting patients at the centre of health care. Brit Med J. 2012;344:256.
6. Barnett SF, Alagar RK, Grocott MP, et al. Patientsatisfaction measures in anesthesia: qualitative systematic review. Anesthesiology. 2013;119(2):452-478.

7. Flierler WJ, Nuebling $M$, Kasper $J$, et al. Implementation of shared decision making in anaesthesia and its influence on patient satisfaction. Anaesthesia. 2013;68(7):713-722.

8. Soltner C, Giquello JA, Monrigal-Martin C, et al. Continu ous care and empathic anaesthesiologist attitude in the preoperative period: impact on patient anxiety and satisfaction. Br J Anaesth. 2011;106(5):680-686.

9. Mui WC, Chang CM, Cheng KF, et al. Development and validation of the questionnaire of satisfaction with perioperative anesthetic care for general and regional anesthesia in Taiwanese patients. Anesthesiology. 2011;144(5):1064-1075.

10. Lauritsen J, Møller AM. Publications in anesthesia journals:quality and clinical relevance. Anesth Analg. 2004;99(5):1486-1491.

11. Saal D, Heidegger $T$, Nuebling $M$, et al. Does a postoperative visit increase patient satisfaction with anaesthesia care? $\mathrm{Br} J$ Anaesth. 2011;107(5):703-709.

12. Myles PS, Williams DL, Hendrata M, et al. Patient satisfaction after anaesthesia and surgery: results of a prospective survey of 10,811 patients. Br J Anaesth. 2000;84(1):6-10.

13. Boulding W, Glickman SW, Manary MP, et al. Relationship between patient satisfaction with inpatient care and hospital readmission within 30 days. Am J Manag Care. 2011;17(1):41-48. 